\title{
Kepentingan Pendidikan Humanistik dalam Pengembangan Psikologi
}

\author{
Khairul Nizam bin Zainal Badri ${ }^{1}$, Hari Khrisnan Andi ${ }^{1}$ \\ ${ }^{1}$ Faculty of Social Sciences, Art \& Humanities, Lincoln University College, Selangor Darul Ehsan, MALAYSIA
}

Received 16 November 2019 • Revised 20 February 2020 • Accepted 10 March 2020

\begin{abstract}
This article aims to analyze the importance of humanistic education from a psychological standpoint. Humanistic education can be considered as a form of education that promotes positive psychological development. The philosophy of Humanistic Education is based on three main theories namely pragmatism, progressivism, and existentialism. When the approach used in humanistic education, it is a dialogical, reflective and expressive approach. The four models of humanistic education that are of concern are learning-based humanities, active classes, quantum classes and learning acceleration. Through humanistic education, human dignity is elevated as much as human intellect can be, and thinking can be further developed. Humanistic education also enlivens human nature through the realization of one's existence. However, humanistic education must be in line with religion so that students will not be confused by the true meaning of freedom. True human values must be based on religion and not on mere logic.
\end{abstract}

Keywords: Humanistik, Psikologis, Potensi

\section{PENDAHULUAN}

Dari segi objek, manusia dipandang sebagai makhluk dengan kemampuan berpikir dan memberdayakan pengalaman. Sedangkan pada subjek, manusia memiliki kemampuan untuk menentukan arah hidupnya. Dalam hal fungsi, manusia bertanggung jawab atas kehidupan mereka serta kehidupan orang lain yang terkait dengan mereka [1]. Secara kolektif, manusia perlu berinteraksi dengan alam dan manusia lain agar perkembangan psikologis dan fisiologis mereka terjadi. Hubungan yang dimaksud bisa dalam bentuk komunikasi atau sosiologi.

Hubungan yang positif akan menumbuhkan hasil pendidikan yang positif. Hubungan menjadi positif ketika dipupuk oleh cinta. Dengan demikian, hubungan yang membangun kebijakan pendidikan yang positif dan efektif berdasarkan proses adopsi manusia ke tingkat manusia disebut pendidikan humanistik [2]. Dasar-dasar pendidikan yang positif dan efektif ini termasuk membawa manusia keluar dari kebodohan dan kegelapan, dengan mengungkap tabir transenden aktual dari sifat manusia itu sendiri.

(c) 2019 by the authors; licensee PGSD UMP. This article is an open access article distributed under the terms and conditions of the Creative Commons Attribution License (http://creativecommons.org/licenses/by/4.0/). $\triangle$ ibnzaynalbadr2016@gmail.com (*Correspondence) $\square$ harikrishnan@lincoln.edu.my. 


\section{FILSAFAT PENDIDIKAN HUMANISTIK}

Filosofi Pendidikan Humanistik didasarkan pada tiga teori utama yaitu pragmatisme, progresivisme, dan eksistensialisme [3]. Pragmatisme melihat pusat pembelajaran sebagai sekolah, sebagai platform kehidupan yang dikelilingi oleh gaya demokratis. Setiap orang dalam kehidupan ini memiliki hak untuk membuat keputusan berdasarkan realitas masyarakat. Poin kuncinya adalah bahwa siswa adalah subjek yang berpengalaman.

Guru dianggap sebagai orang yang tidak "tahu" kebutuhan siswa di masa depan. Kurikulum pembelajaran didasarkan pada proses pembelajaran, bukan hasil belajar. Metode pembelajaran harus memberi siswa kebebasan untuk memperoleh pengalaman sebanyak mungkin. Fleksibilitas pendidikan harus mampu mengatasi perubahan sosial saat ini [4].

Progresivisme juga menekankan kebebasan aktualisasi diri agar menjadi kreatif. Selain itu, ini juga menekankan pada kebutuhan dan minat siswa. Untuk tujuan itu siswa harus proaktif dalam pengalaman hidup mereka. Adaptasi yang kreatif untuk memenuhi kebutuhan yang lahir dari sikap proaktif. Dengan kata lain, siswa yang tidak terlalu terikat pada buku dan guru malah menjadikan pengalaman sebagai salah satu cabang untuk menambah pengetahuan [5].

Eksistensialisme menekankan konsep individualisme. Dengan kata lain, keunikan siswa dilihat sebagai individu daripada sebagai unit sosial. Teori ini memfasilitasi eksplorasi makna perilaku siswa dan menghubungkannya dengan pengambilan keputusan. Siswa memiliki kebebasan untuk memilih, tetapi pada saat yang sama, bertanggung jawab atas keputusan yang mereka buat. Teori ini menganggap kebebasan sebagai kekuatan yang sangat kuat untuk mewujudkan potensi seseorang ke tingkat yang lebih tinggi [6].

Teori eksistensialisme ini dikatakan muncul untuk membangkitkan kembali kemanusiaan yang dimatikan oleh pemikiran pendidikan yang cenderung memenuhi persyaratan industri. Siswa tidak diberi kesempatan untuk mengembangkan potensi mereka karena sistem pendidikan lebih memilih kurikulum yang berorientasi pada perusahaan dan sangat birokratis. Dengan teori eksistensialisme, sifat keingintahuan dapat dihidupkan kembali. Sikap ini penting karena menciptakan rasa keinginan untuk belajar. Eksistensialisme juga dapat menciptakan lingkungan belajar yang kondusif karena ruang kebebasan yang luas yang memungkinkan siswa untuk menjadi kreatif dan aktif [7].

Tabel 1. Teori-teori yang terdapat dalam pendidikan humanistik

\begin{tabular}{cc}
\hline Teori & Kelebihan \\
\hline Pragmatisme & Kebebasan hak \\
\hline Progresivisme & $\begin{array}{c}\text { Kebebasan } \\
\text { aktualisasi diri }\end{array}$ \\
\hline \multirow{2}{*}{ Eksistensialisme } & $\begin{array}{c}\text { Menghidupkan } \\
\text { nilai-nilai } \\
\text { kemanusiaan }\end{array}$ \\
\hline
\end{tabular}




\section{PENDEKATAN PENDIDIKAN HUMANISTIK}

Pendekatan yang digunakan dalam pendidikan humanistik adalah pendekatan dialogis, reflektif dan ekspresif. Pendekatan dialogis mengacu pada pemikiran kreatif dan kritis. Fungsi guru selain memberikan konten pembelajaran kepada siswa juga melibatkan bimbingan dalam bentuk keterampilan komunikasi [8].

Pendekatan reflektif, pada gilirannya, membentuk kepribadian siswa dengan membangun kepercayaan pada siswa mereka dengan menggunakan bakat dan keterampilan yang ada untuk meningkatkan kegiatan pembelajaran yang telah diarahkan guru [9]. Perbedaan antara ekspresif dan ekspresif adalah bahwa ekspresif melibatkan pengembangan potensi dengan merealisasi dan mengaktualisasi bakat dan keterampilan mereka melalui konten pembelajaran yang dihasilkan [10].

Sejalan dengan slogan humanistik, pendidikan harus menekankan komunikasi dan pembentukan pribadi dalam kelompok sosial. Dengan demikian, pendidikan tidak boleh dipandang sebagai transfer pengetahuan belaka, tetapi harus dicatat bahwa perkembangan siswa adalah optimal sesuai dengan aspirasi pendidikan itu sendiri. Siswa diberi kebebasan untuk mengembangkan potensi mereka. Guru bertindak sebagai katalis untuk mewujudkan potensi murid-muridnya.

Pendekatan semacam itu menciptakan lingkungan belajar yang kondusif karena siswa diberi kesempatan untuk menempatkan diri di antara hadirin, sesuai dengan potensi mereka. Siswa menerima pengiktirafan dan apresiasi dari guru mereka dan yang paling penting penerimaan mereka di antara hadirin.Pada saat yang sama, siswa dapat berfungsi secara optimal di antara hadirin. Karena itu, inilah tujuan sebenarnya dari pendidikan. Siswa hebat tidak hanya cerdas secara akademis dan olahraga, tetapi juga harus dianggap humanis [11].

Tabel 2. Pendekatan yang digunakan dalam pendidikan humanistik beserta fungsinya

\begin{tabular}{cc}
\hline Pendekatan & Fungsi \\
\hline Dialogik & $\begin{array}{c}\text { Menjadikan siswa } \\
\text { berfikiran kreatif } \\
\text { dan kritis }\end{array}$ \\
\hline Reflektif & Membina \\
& $\begin{array}{c}\text { kepribadian diri } \\
\text { siswa }\end{array}$ \\
\hline Ekspresif & $\begin{array}{c}\text { Merealisasikan dan } \\
\text { mengaktualisasikan } \\
\text { bakat }\end{array}$ \\
\hline
\end{tabular}




\section{MODEL PENDIDIKAN HUMANISTIK}

Di antara model Pendidikan Humanistik yang digunakan dalam pembelajaran adalah

1. Humaniora berbasis pembelajaran

Atmosfer yang kondusif akan menyuntikkan proses pertumbuhan ke dalam lingkungan yang halus dan terus berubah. Perubahan yang dimaksud meliputi pengenalan konsep dan identitas serta integrasi kesadaran dan pikiran. Keterlibatan dalam kelas merangsang naluri manusia untuk memilih dan membuat keputusan [12]

2. Pembelajaran aktif

Pembelajaran ini melibatkan aktivitas mental dan respons secara bersamaan. Aktif berarti siswa belajar ide, memecahkan masalah dan merumuskan apa yang telah mereka pelajari. Model ini mencakup diskusi yang melibatkan penggunaan pendengaran dan penglihatan untuk memahami suatu topik atau subjek. Penguasaan pengetahuan dikatakan lebih mudah dicapai karena penggunaan pendengaran dan penglihatan dapat mempercepat proses pemahaman [13]

3. Pembelajaran kuantum

Tujuan utama dari pembelajaran ini adalah untuk menciptakan jembatan antara pikiran dan emosi sehingga siswa dapat melakukan lompatan untuk mencapai hal yang tidak terduga. Intelegensi berfungsi menyerap informasi dan merekamnya dalam bentuk pengetahuan. Metode ini untuk terlibat dalam berbagai bentuk interaksi yang dapat memicu inspirasi untuk menyelaraskan antara pikiran dan hati [14]

4. Akselerasi pembelajaran

Dalam model ini, guru menggunakan empat pendekatan utama: belajar melalui kepraktisan, belajar dengan mendengarkan dan berbicara, belajar dengan observasi dan deskripsi dan belajar dengan pemecahan masalah dan refleksi dengan memecahkan masalah [15]

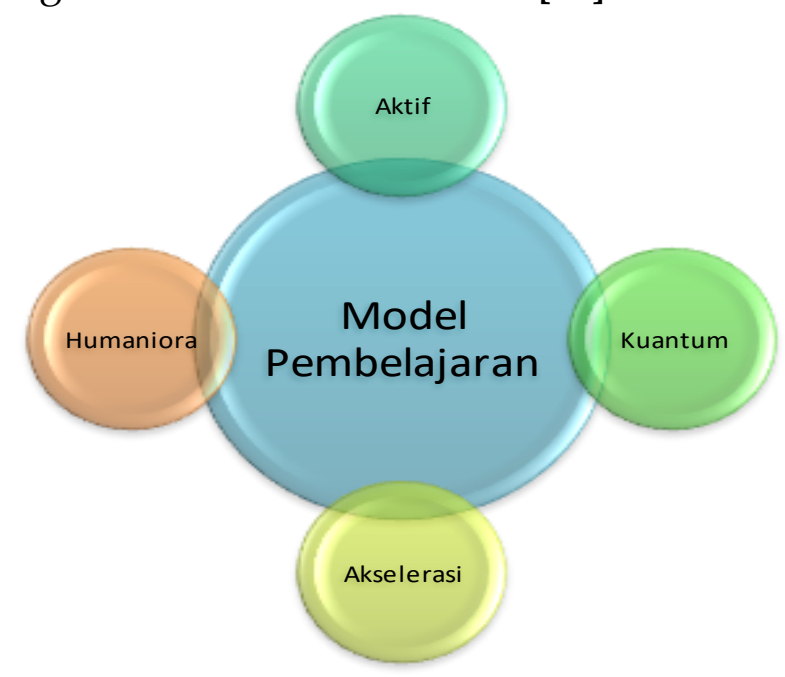

Gambar 1. Model-model pembelajaran humanistik 


\section{KEPERLUAN PENDIDIKAN HUMANISTIK DALAM PENGEMBANGAN PSIKOLOGI}

Dari sudut pandang humanis, manusia dianggap sebagai pusat aktivitas dalam kehidupan. Manusia dipandang dari semua sudut dan dianggap makhluk multidimensi [16]. Dua dimensi utama adalah fisik dan spiritual. Yang membedakan orang dari makhluk lain adalah dimensi spiritual. Dimensi ini terkait erat dengan psikologi manusia [17].

Jika spiritualitas dapat dikembangkan maka psikologi akan berkembang juga. Untuk alasan ini, pertumbuhan spiritualitas berdampak pada kesehatan mental manusia terutama dalam kaitannya dengan kecerdasan [18].

Kecerdasan ideal terjadi ketika perilaku psikologis dan prestasi akademik siswa seimbang. Kecerdasan tidak boleh berakibat fatal karena potensi dan bakat seseorang berbeda satu sama lain. Kecerdasan spiritual dan fisik yang seimbang akan meningkatkan perilaku psikologis dan prestasi akademik.

Setidaknya ada 7 jenis kecerdasan yang hadir dalam diri manusia yaitu kecerdasan logis, kecerdasan bahasa, kecerdasan komunikasi, kecerdasan gerak, kecerdasan suara, kecerdasan visual, dan refleksi terkait batin. Dengan kecerdasan ini, manusia dapat mengembangkan potensinya dari sudut penciptaan, kekuatan kemauan dan kekuatan produksi [19]. Mengembangkan potensi akan menarik siswa ke komunitas kemanusiaan dengan bekerja di dalam komunitas daripada di dalam diri mereka sendiri.

Dalam sistem pendidikan, humanistik dianggap sebagai pendekatan yang membantu siswa untuk menjadi manusia. Tujuannya adalah untuk mengembangkan esensi dan potensi yang optimal untuk mengaktualisasikan diri menjadi manusia. Konsep utama dalam pendidikan adalah menghormati martabat manusia. Dalam pendidikan ini, lingkungan belajar bebas dari persaingan, persaingan tinggi dan takut gagal. Dengan kata lain, tidak ada istilah penindasan dalam pendidikan humanistik [20]. Siswa dipersiapkan untuk memahami masalah mendasar dan esensial yang berkaitan dengan realitas kehidupan daripada berfokus terlalu banyak pada penguasaan teknik industri.

Pendidikan humanistik mengubah suasana pendidikan yang didorong oleh tekanan peperiksaan atau ketakutan akan kesalahan menjadi rasa aman dan percaya diri sehingga siswa merasa percaya diri dalam melahirkan kreativitas dan minat mereka untuk belajar.

Melalui pendidikan humanistik, ujian bukanlah penentu absolut dari prestasi siswa tetapi konsep keterbukaan memungkinkan siswa untuk mengembangkan potensi mereka sesuai dengan kebutuhan dan minat mereka. Dengan demikian, aspirasi pendidikan kembali ke pengembangan harga diri daripada fokus pembelajaran yang hanya didasarkan pada pencapaian ujian. 


\section{REKONSILIASI NILAI-NILAI HUMANISTIK DALAM PENDIDIKAN}

Ketika humanistik dipopulerkan oleh tokoh-tokoh Barat, masalahnya adalah anggapan bahwa manusia diposisikan sebagai makhluk yang paling kuat. Kaum humanis di Barat menganggap kebebasan sebagai hak mutlak yang tidak seorang pun dapat menyerbu [21]. Kebebasan juga merupakan masalah ketika dikaitkan dengan keadilan, terutama dari sudut pandang etika. Oleh karena itu, kebaikan dianggap sebagai sesuatu yang relatif, yang berubah sesuai dengan perspektif manusia.

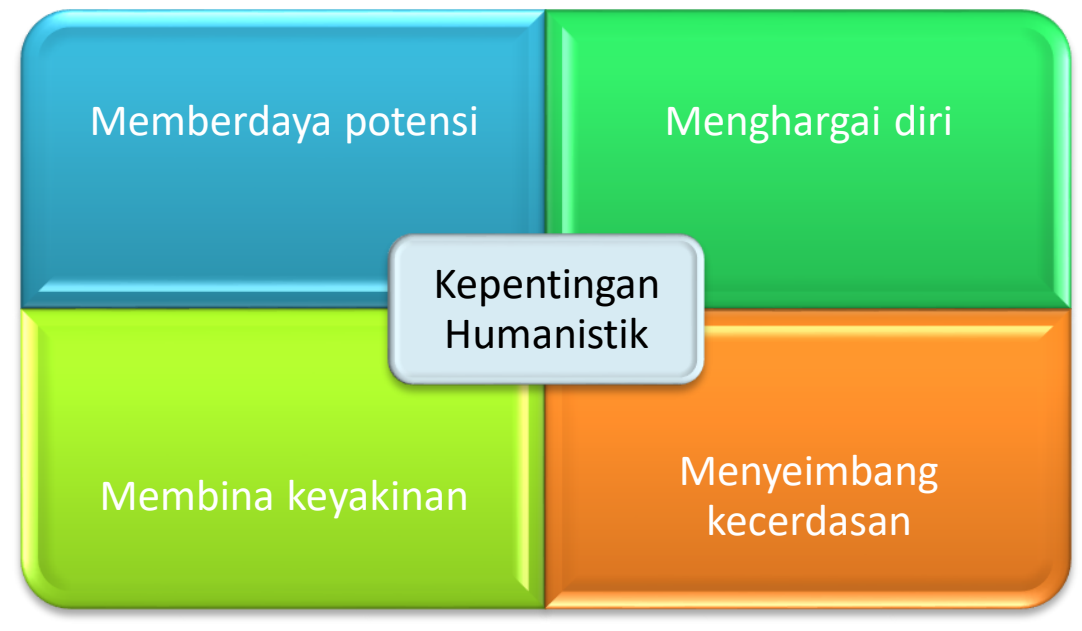

Gambar 2. Kepentingan pendidikan humanistik dalam usaha pengembangan psikologi

Dalam pendidikan, memahami kebebasan seperti itu tampaknya menyebabkan banyak masalah bagi siswa. Ini karena siswa terkeliru oleh batasan yang harus dia perhatikan. Kebebasan tidak mutlak karena dapat mempengaruhi pemikiran siswa, terutama anak-anak dan remaja.

Teori Pembelajaran Sosial yang dikembangkan oleh Albert Bandura terkenal dengan pendidikan humanistiknya. Teori ini menekankan prinsip "Tidak bisa mengatakan tidak kepada anak-anak". Prinsip-prinsip ini, pada kenyataannya, sangat baik untuk merangsang keterampilan berpikir siswa. Tetapi pada saat yang sama membingungkan siswa karena mereka tidak dapat memahami perbedaan antara sesuatu atau tindakan apakah itu sah atau ilegal, atau berdosa atau tidak [22].

Di sini jelas terlihat cacat pendidikan humanistik yang tidak dapat secara akurat mendefinisikan makna kebebasan. Pendidikan humanistik, sebagian besar didasarkan pada kerangka filosofis Barat, menempatkan kebebasan sebagai sesuatu yang tidak terikat pada aturan atau nilai apa pun termasuk agama. Ini karena jika kebebasan dibatasi oleh aturan atau nilai-nilai, maka ia bertentangan dengan prinsip-prinsip kemanusiaan. 
Dalam hal ini, rekonsiliasi antara humanistik dan agama harus dilakukan agar pendidikan diarahkan pada kebenaran. Dalam Islam, tuntutan agama harus sejalan dengan sifat pembentukan pribadi manusia. Oleh karena itu, pendidikan humanistik perlu diselaraskan dengan agama sehingga siswa dapat memahami makna kebebasan tanpa mengurangi aspek pengembangan potensi mereka dari sudut pandang perilaku psikologis dan fisiologis. Pendidikan humanistik yang berorientasi pada agama akan memiliki nilai tambah karena agama akan membangun nilai-nilai moral saperti adab dan akhlak kepada siswa [23].

Demikian pula, kecerdasan spiritual, dipahami dalam kerangka Barat, memiliki interpretasi yang tidak konsisten dan sangat relatif. Meskipun Barat percaya pada keberadaan dimensi spiritual, itu terpisah dari agama [24]. Ini karena Barat melihat kecenderungan manusia untuk berubah dengan waktu, lingkungan dan waktu [25]. Perubahan ini menurut Barat harus independen, yang tidak dapat diblokir. Dari sudut pandang agama, kecerdasan spiritual berhubungan langsung dengan kepercayaan akan keberadaan Tuhan. Oleh karena itu, kepercayaan ini mengikat orang untuk menahan diri dari melakukan hal-hal yang salah dalam agama mereka, meskipun mereka tidak dalam pandangan publik.

Rasionalisasi kecerdasan spiritual di Barat mengarah pada penggunaan sementara nilai-nilai duniawi. Dimensi spiritual yang terhubung dengan kekuatan intelek masih terpapar kebingungan dalam mengejar kebenaran. Ini adalah kebenaran dalam konteks kerangka Barat yang masih spekulatif daripada religius. Agar kecerdasan dihubungkan dengan kebenaran autentik, maka pemahaman agama harus diintegrasikan dengan humanistik.

\section{AGAMA SEBAGAI JEMBATAN HUMANISTIK DALAM PENGEMBANGAN PSIKOLOGI}

Prinsip-prinsip humanistik dianggap sangat sesuai dengan Islam karena Islam mengangkat kemanusiaan sesuai dengan posisinya sebagai kekhalifahan di bumi. Namun, perbedaan antara Islam dan Barat adalah bahwa Islam percaya bahwa ada kekuatan lain bagi manusia yaitu pencipta dunia ini. Oleh karena itu, tugas manusia di bumi ini adalah untuk memenuhi tugasnya sebagai hamba kepada Tuhan dengan mengatur kehidupan di bumi ini sesuai dengan hukum Allah. Agar manusia dapat mengatur hidup mereka, mereka diberkahi dengan empat atribut utama yaitu

1. Basyar - manusia sebagai makhluk biologis dengan potensi fisik dan psikologis

2. Al-Nas - manusia sebagai makhluk sosial yang diciptakan berpasangan, bangsa dan suku dengan tujuan untuk saling mengenal

3. Bani Adam - manusia sebagai makhluk rasional dengan kemampuan berpikir untuk meningkatkan kesejahteraan mereka

4. Al-Insan - manusia sebagai makhluk spiritual yang memiliki hubungan langsung dengan Penciptanya. Karena itu, sebagai hamba, manusia harus mengabdikan dirinya kepada tuannya dengan menyembahnya. Sebagai 
makhluk spiritual, manusia perlu percaya bahwa Tuhan memegang kendali penuh atas kehidupan dunia. Dengan keyakinan seperti itu, manusia percaya bahwa Tuhan telah memberikan aturan terbaik untuk kehidupan dunia. [26]

Dalam konteks psikologi modern, sifat Basyar terkait erat dengan dasar biologi yang memberikan wawasan tentang kecerdasan paling dasar yang terdiri dari neuropsikologi (fungsi otak), elektrofisiologi (aktivitas listrik dari seluruh otak) dan aliran darah [27]. Sifat al-Nas terkait erat dengan interaksi sosial di mana pengetahuan diperoleh melalui pembelajaran sosial. Kecerdasan meningkat ketika interaksi dengan orang-orang di sekitarnya meningkat [28]. Sifat Bani Adam ketika dipetakan dalam psikologi modern mengacu pada perkembangan kognitif yang melibatkan proses membangun dan memanipulasi pengetahuan dengan cara yang bijaksana. Membangun pengetahuan ini secara aktif terlibat dan mungkin melibatkan interaksi dengan lingkungan [29]. Akan tetapi, sifat al-Insan tidak dapat dipetakan secara tepat dalam psikologi modern meskipun Barat mengakui perlunya integrasi intelektual dalam pengembangan psikologi manusia, terutama dalam konteks spiritualitas [30]. Di sinilah kebutuhan akan agama terletak pada menjembatani pendidikan humanistik dengan perkembangan psikologi manusia.

Dalam Islam, kebenaran berhubungan langsung dengan basis pengetahuan. Ini karena kebenaran adalah proses mendapatkan pengetahuan. Kebenaran dikatakan mengembangkan psikologi manusia karena kebenaran adalah kesadaran akan keberadaan Tuhan. Dengan demikian, kebenaran adalah upaya sadar aktif.

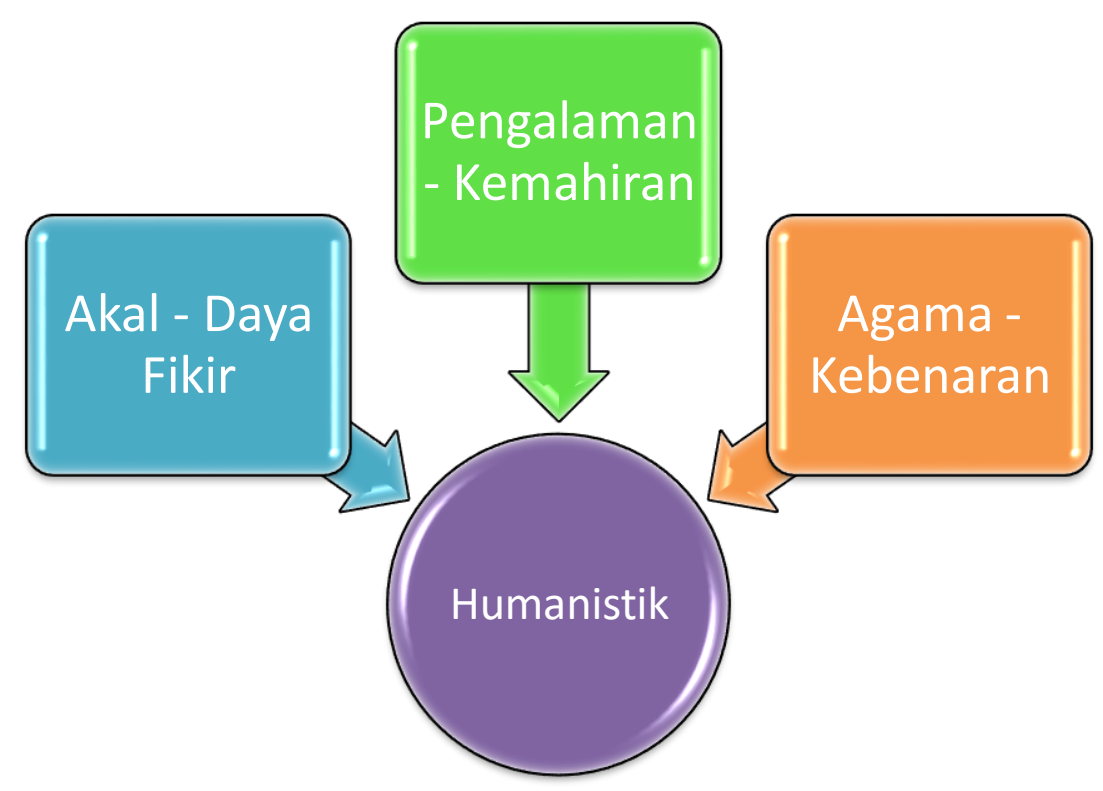

Gambar 3. Tiga elemen penting dalam pendidikan humanistik bagi mengembangkan psikologi 


\section{KESIMPULAN}

Manusia dianggap sebagai pusat aktivitas dalam kehidupan dan dianggap makhluk multidimensi. Dua dimensi utama adalah fisik dan spiritual. Keberadaan dua dimensi ini dalam tubuh manusia menunjukkan bahwa manusia memiliki potensi internal dan eksternal. Potensi internal dianggap lebih penting karena berkaitan dengan psikologi manusia. Jika psikologi manusia dalam kondisi baik maka perilaku manusia akan diarahkan pada tindakan positif.

Kedua-dua potensi tersebut mestilah dikembangkan dengan baik. Oleh karena itu, salah satu peluang pendidikan terbaik untuk mengembangkan potensi tersebut adalah dengan menerapkan pendidikan humanistik. Menerusi pendidikan humanistik, potensi siswa dapat dikembangkan sejalan dengan pendekatannya yang meningkatkan martabat manusia dan kemampuan untuk mengembangkan ide-ide. Meskipun demikian, pendidikan humanistik harus diimbangi dengan pemahaman agama.

Pemahaman agama sangat penting karena membatasi tingkat kebebasan manusia yang boleh terkeliru dengan definisi kebaikan. Kebaikan di pihak manusia belum tentu kebenaran tetapi kebaikan di mata Tuhan adalah kebenaran yang benar. Sebagai contoh, agama melarang seks bebas antara pria dan wanita karena dikhawatirkan mereka akan terjebak dalam hubungan yang belum menikah, meskipun itu mungkin dianggap tidak berbahaya bagi pria dan wanita.

\section{REFERENCES}

[1] Mas'ud, A. (2002). Menggagas Format Pendidikan Nondikotomik; Humanisme Relegius Sebagai Paradigma Pendidikan Islam. Yogyakarta: Gema Media.

[2] Sukardjo, \& Komarudin, U. (2009). Landasan Pendidikan, Konsep dan Aplikasinya. Jakarta: PT. Raja Grafindo Persada.

[3] Knight, G. R. (1982). Issues and Alternatives in Educational Philosophy. Michigan: Andrew University Press.

[4] Sharma, S., Devi, R., \& Kumari, J. (2018). Pragmatism in Education. International Conference on New Frontiers of Engineering, Science, Management and Humanities (ICNFESMH-2018) (pp. 74-79). Hisar, India: OM Institute of Technology \& Management.

[5] Zucca-Scott, L. (2010). Know Thyself: The Importance of Humanism in Education. Internatonal Education , 40 (1), 32-38.

[6] Yahyaei, D., \& Mahini, F. (2017). The Influence of existentialism on teaching methods. International Journal of Learning and Teaching , 9 (3), 354363.

[7] Mozaffari, M., \& Jahanian, R. (2016). Identifying Existentialist Philosophy of Education. International Academic Journal of Social Sciences , 3 (8), 18-28.

[8] Firdaus, F. A., \& Mariyat, A. (2017). Humanistic Approach In Education 
According to Paulo Freire. At-Ta' dib , 12 (2), 25-48.

[9] Rideout, G. W., \& Koot, R. A. (2009). Reflective, Humanistic, Effective Teacher Education: Do Principles Supported in the Deans' Accord Make a Difference in Program. Canadian Journal of Education , 32 (4), 927-956.

[10] Carvalho, R. J. (1991). The humanistic paradigm in education. The Humanistic Psychologist, 19 (1), 88-104.

[11] Magill, K., \& Rodriguez, A. (2014). A Critical Humanist Curriculum. Journal for Critical Education Policy Studies , 205-227.

[12] Arifi, Q. (2017). Humanistic Approach in Teaching Foreign Language (from the Teacher Perspective). European Scientific Journal , 13 (35), 194-205.

[13]Sharp, A. (2012). Humanistic Approaches to Learning. In N. M. Seel, Encyclopedia of the Sciences of Learning. Boston: Springer.

[14]Zeybek, G. (2017). An investigation on quantum learning model. International Journal of Modern Education Studies , 1 (1), 16-27.

[15] Rasiman, K., Dina, P., \& Didik, F. (2016). Humanistic Mathematics Learning Assisted by Interactive CD using SAVI approach to Increase Students' Critical Thinking Skill. Global Journal of Pure and Applied Mathematics , 12 (4), 3683-3692.

[16] Alkire, S. (2002). Dimensions of Human Development. World Development , 30 (2), 181-205.

[17]Sujati, H. (1995). Hakekat Manusia dan Implikasinya Terhadap Pendidikan. Dinamika Pendidikan , 2 (1), 29-36.

[18]Razak, A. L. (2012). The Islamic Worldview on the preservation and restoration of mental health. In A. H. Solihu, The Islamic Worldview, Ethics and Civilization: Issues in Contemporary Interdisciplinary Discourse (pp. 7796). Kuala Lumpur: IIUM Press.

[19] Gardner, H. (1993). Multiple Intelligences: The Theory in Practice. New York: Basic Books.

[20]Osman, A. A. (2013). Freedom in Teaching and Learning. International Journal of Humanities and Social Science, 3 (2), 142-149.

[21]Skirbekk, G., \& Gilje, N. (2001). A history of Western thought from Ancient Greece to the Twentieth Century. London: Routledge.

[22] Badri, M. (1979). The Dilemma Of Muslim Psychologists. London: MWH London.

[23]Jumarudin, Gafur, A., \& Suardiman, S. P. (2014). Pengembangan Model Pembelajaran Humanis Religius Dalam Pendidikan Karakter Di Sekolah Dasar. Jurnal Pembangunan Pendidikan: Fondasi dan Aplikasi , 2 (2), 114-129.

[24] Attri, R. (2012). Spiritual Intelligence: A model for inspirational. Research Journal of Social Science \& Management , 1 (9), 212-219.

[25]Qutb, S. (1991). The Islamic Concept and Its Characteristics. Indiana: American Trust Publications.

[26] Arbayah. (2013). Model Pembelajaran Humanistik. Dinamika Ilmu , 13 (2), 204-220.

[27] Sternberg, R. (1988). The triarchic mind: A New theory of human intelligence. New York: Viking. 
[28] Vygotsky, L. (1978). Mind in Society. Cambridge MA: Harvard University Press.

[29]Smock, C. D. (1981). Constructivism and educational practice. In J. Sigel, D. Brodzinsky, \& R. Golinkoff, New directions in Piagetian theory and practice (pp. 51-69). Hillsdale NJ: Lawrence Erlbaum Associates.

[30]Cohen, L., \& Ambrose, D. (1993). Theories and practices for differentiated education for the gifted and talented. In K. Heller, F. Monks, \& A. Passow, International handbook of research and development of giftedness and talent (pp. 339-363). New York: Pergamon.

http://jurnalnasional.ump/index.php/dinamika 